\title{
Simulation and Modeling Applications in Global Health Security
}

\author{
Arthur J. French
}

\section{Introduction}

Global health security (GHS) is dependent upon having an adequate and prepared health security workforce. There are currently numerous challenges in establishing and maintaining a health security workforce. The frequency and magnitude of disasters have increased significantly over the past 30 years. Current and future GHS threats, both manmade and natural, require a prepared and flexible healthcare provider workforce ready to respond to current or emerging GHS threats [1]. Developing and maintaining GHS -specific skills in the healthcare workforce is a tremendous logistical challenge. Innovative education technologies, including simulation and digital learning, can be leveraged to achieve preparedness for GHS threats [2].

Ebola Virus Disease (EVD), Middle East Respiratory Syndrome (MERS) and other emerging infectious diseases (EID) are also concerns for GHS. The world faces increasing challenges related to natural and manmade disasters as the frequency and magnitude of disasters have increased significantly over the past 30 years. Healthcare workers protect the well-being of people around the world by preventing, detecting, and responding to public health threats. Current and future GHS threats, both manmade and natural, require a prepared and flexible healthcare provider workforce ready to respond to current or emerging threats [3].

There is a global public health workforce shortage. The WHO tracks healthcare workforce data on 186 countries, and 57 were insufficient in healthcare provider availability and accessibility [4]. The 2013-2016 African EVD epidemic revealed WHO organizational deficiencies in coordinating responses to public health emergencies and a shifting of priorities away from global health security threats [5]. It

\footnotetext{
A. J. French $(\bowtie)$

College of Public Health, University of South Florida, Tampa, FL, USA

e-mail: ajfrench@aeromd.global
} 
also revealed gaps in response capabilities to deploy adequate numbers of medical, logistical, and public health experts [6,7]. It has been estimated that over 1000 deployed healthcare workers would be needed each month in West Africa and stated that innovative means would be needed to prepare for future GHS responses [8].

The United Nation's Global Burden of Disease 2017 Study reported information on countries' health workers capacity. The study authors estimated that only approximately $50 \%$ of countries met their estimated requirement for health-care workers. Developing countries in Africa, southeast Asia, and Oceania suffered the largest population-based relative gaps and are the most vulnerable [9].

GHS is a critical public health workforce mission. While medicine has made great advances in preventing and treating infectious diseases, these advances have been offset by new EID threats including SARS, EVD, and MERS. These emerging and re-emerging public health crises have identified gaps in public health capabilities and generated recommendations to globally strengthen public health's pandemic preparedness [10].

The Global Health Security Agenda (GHSA) was launched in 2014 to establish a world-wide coalition of 44 nations to address the re-emergence of threats from infectious disease epidemics and pandemics, including bioterrorism. Participating countries agreed to define and measure milestones of progress and metrics [3]. GHS is a critical component of nations' security interests [11].

There is an increased requirement for public health professionals being prepared to respond to complex humanitarian emergencies and public health emergencies of international concern (PHEICs), creating a supply versus demand gap. This gap will grow due to an insufficient public health workforce and increased requirements with the concomitant threats of increased epidemics and pandemics to disrupt international economies and political destabilization.

\section{Global Health Security Workforce Competency Challenges}

In 2016 the world health organization announced the process of developing and launching emergency medical teams (EMTs), a critical component of the GHS workforce concept. Over 64 countries are in the development stages of establishing accredited teams, both international and national, to deliver emergency clinical care to sudden onset disasters and outbreak affected populations. EMTs must comply with the classification of minimum standards for EMTs developed in 2013 by the WHO Foreign Medical Team Working Group in the Global Health Cluster. Not infrequently, health providers have had to learn quickly that their specialty training alone was not enough that they lack the operational skills sets and collaborative leadership capacity required for the demands of resource, poor decision-making during the complexities of public health emergencies such as epidemics. Under the EMT concept all countries share the responsibility to ensure that cross disciplinary, 
competency-based knowledge in field-related tasks to practice globally with high standards of care [12] An essential component to improve WHO EMT quality and accountability of national and international EMTs is appropriate education and training. Multiple disaster education and training programs are available, however, most are centered on individual professional development rather than on the EMTs operational performance. No common overarching or standardized training framework exist [13]. A proposed three-step learning process approach for EMTs is: (1) professional competence; (2) adaptation to the operational context; and (3) team performance. Training delivery should go from theory to practice and from individual to team training [14].

In addition to the shortages of GHS workers there are gaps in their competencies to respond to PHEICs. There are multiple reasons for the GHS preparedness gap. There are few formal training programs for disaster responders, particularly in clinical training and few U.S. public health graduate programs address humanitarian assistance $[15,16]$. Most training is focused on traditional individual skills and not on unique response-related operational competencies for PHEICs.

Developing and maintaining skills needed during a PHEIC presents a tremendous logistical challenge. Many of these skills are unique to health security events and are new skills and knowledge that must be adapted to dynamic situations, particularly infectious disease outbreaks. They also must be performed in resource-constrained environments, requiring adaptation of unfamiliar crisis standards of care by healthcare providers [17]. An additional challenge for healthcare responders is the deterioration of previously learned knowledge and skills. Competency and skill retention are important components of training in infrequently used procedures. Innovative education technologies, including simulation, can be leveraged as a GHS healthcare force multiplier.

Experience responding to disasters alone is not sufficient. Previous experience with international disaster relief needs to be combined with disaster medicine training. There is a need to develop a universal tool for measuring physician skills in international disaster relief because of the difficulties in evaluating the medical relief activities of disaster medical teams. Skills change in accordance with differences in demographic characteristics, previous experiences, and disaster situations [18].

Because of the immense variation in the nature and magnitude of health security events the boundaries of specific healthcare provider disciplines' skills are imprecise [19]. To prepare GHS responders to meet these challenges, various organizations and universities have developed competencies for healthcare responders. In 2008 the American Medical Association published a consensus-based and multidisciplinary educational framework for disaster medicine and public health preparedness defining 19 core competencies. Healthcare responders were assigned to three levels of proficiency: Informed worker/student, practitioner, and leader. This approximates the ascending levels of application and synthesis of knowledge in Bloom's taxonomy of learning [20]. Core disaster competencies aligned with the six levels of proficiency established in Blooms taxonomy have been proposed by others also $[19,21]$. 


\section{Simulation Based Training: A GHS Force Multiplier}

Providing initial and sustainment training to the diverse GHS healthcare workforce is expensive and inefficient utilizing the traditional classroom model. Greater demands have been placed on disaster medicine educators. There is a need to develop innovative methods to educate healthcare providers in the ever-expanding body of disaster medicine knowledge [22].

Many of these challenges can be met with gaming and simulation technologies new generations of GHS responders have embraced. Simulation-based training (SBT) has been demonstrated to provide effective learning and is increasingly being integrated into healthcare provider education [23]. The advantages of SBT may be summarized as follows: (1) safety- simulated lives and health can be jeopardized to any extent required for training without harming any people; (2) economy- simulated material and equipment can be used, misused, and expended; (3) visibility- simulation can provide visibility in two ways; you can make the invisible visible and control the visibility of details allowing the learner to discern the forest from the trees or the trees from the forest as needed; (4) time control -simulator time can be sped up, slowed down, or stopped. It can also be completely reversed, allowing learners to replicate specific problems, events, or operational environments as needed [24].

SBT has been institutionalized in other high hazard professions, such as aviation, nuclear power, and the military. GHS responders often have few opportunities for critical skill development and sustainment. Simulation can provide just-in-time training and refresher training, which potentially would reduce decay of critical skills. Simulation can also reach individuals wherever they are during mobilization for disaster relief in remote areas, including team training of individuals even before the team is geographically assembled. GHS training must balance the use of technology, with its probable absence in operational environments. This is analogous to the U.S. Department of Defense (DOD) military services and others who operate in remote and austere environments where technology, including telementoring and decision support tools, may not be available. DOD has invested in computer games and simulation technology for increased training effectiveness and patient safety, with reduced training costs through increased preparation of personnel before costly field training exercises and reduction in total training time [25].

Medical training has traditionally used patients to hone the skills of health professionals, balancing the obligations to provide optimal treatment and to ensure patients' safety. SBE can mitigate this tension by developing health professionals' knowledge, skills, and attitudes while protecting patient patients, maximize training safety, and minimize risks. Expanding use of SBT in GHS training can be considered an ethical imperative [26].

David Gaba, a leader in the field of medical simulation, defined simulation as "a technique not a technology to replace or amplify real experiences with guided experiences that evoke or replicate substantial aspects of the real world and a fully interactive manner." [27] Simulation is a person, device, or set of conditions which 
attempts to present educational and evaluation problems authentically. Learners are required to respond to the problems as he or she would under natural circumstances. High fidelity medical simulations facilitate learning under the right conditions of: 1) providing feedback 2) repetitive practice 3) curriculum integration 4) a range of difficulty 5) multiple learning strategies 6) a controlled environment 7) individualized learning; 8) defined outcomes 9) and simulator validity. These conditions maximize the impact of simulation-based training [23].

Simulation provides a range of educational tools. A growing number of computer screen simulations, high fidelity manikins, and virtual reality simulators have expanded the number of procedures and disaster conditions which can effectively simulated [28]. In many, but not all, instances SBT can be the best tool for achieving learning objectives. Simulation create "perfect practice" environments. Advanced technology has been engineered into large-scale production of simulators capable of modeling a wider variety of clinical scenarios [29] Responding to changing GHS environments requires new paradigms for training. Simulation technologies encompass diverse products including computer-based virtual reality simulators, high fidelity and static manikins, task trainers, live animals, animal products, and human cadavers. In comparison with no intervention, technology-enhanced simulation training is consistently associated with large effects for outcomes of knowledge, skills, and behaviors [30].

The important questions for GHS educators are when and how to implement SBT most effectively and cost efficiently. SBT has demonstrated effectiveness in training healthcare workers for complex humanitarian emergencies and EIDs [15, 31]. Implementation science addresses the mechanisms of education delivery in healthcare. The aim of implementation sciences is to study and seek to overcome healthcare organizational silos and barriers, pockets of cultural inertia, professional hierarchies, and financial disincentives that reduce efficiency and effectiveness [32]. GHS leaders need to be knowledgeable in the fundamentals of SBT theories and modalities, and innovative in SBT strategies to overcome implementation barriers.

\section{Simulation Learning Theories}

Adult learning theory serves as the foundation for SBT. Effective SBT of adults requires a sound understanding of adult learning theory and experiential learning. Mental models form the basis for operational decision-making. GHS educators can design simulation scenarios to stress existing mental models, helping individuals to identify areas where they need and want to learn.

Malcolm Knowles developed the andragogy conceptual framework for adult learning. This framework about adult learners must be considered when developing simulation programs. These assumptions about adult learners are: (1) Adults need to know why they need to learn something before undertaking the effort to learn; (2) adults have a self-concept bias towards independent and self-directed learning; (3) adults have acquired a great deal of life experience that help shape adults self-identity; (4) adults 
value learning that helps them cope with the demands of their everyday life; (5) adults are more interested in life centered or problem centered approaches than subject centered approaches to learning; (7) adults are more motivated to learn by internal drives than external ones, including self-efficacy. For effective SBT there needs to be a strong sense of a safe learning environment where the participants do not feel threatened to make mistakes and mistakes are used for teachable moments opportunities rather than embarrassing the learners. This safe learning environment must be established during the orientation to the simulation environment [33].

Simulation incorporates the evidence-based learning theories of Kolb's experiential learning cycle $[33,34]$. Kolb described learning as a continuous reflective process grounded in concrete experience and a continuous adaptation of what a person actually experiences in the world. Reflection is the ability to learn and develop continually by applying current and past experience experiences to unexpected events. Simulation is able to provide repeat and consistent experiences with the expected or unexpected [35]. Simulation-based mastery learning is a form of competency-based education which all learners acquire essential skill and knowledge measured rigorously in relation to high-end fixed achievement standards without restricting learning time to uniform interval to reach the outcome. The education goal of mastery learning is excellence for all learners.

A key concept in this conceptual framework is the formation and maintenance of learner self-efficacy, the belief in one's capabilities to organize and execute the courses of action needed to manage prospective situations. Self-efficacy relates to believing in oneself to take action [35]. Errors trigger stress and emotional responses from learners and can be a strong stimulus for learning. Most learners can recall what they did incorrectly because a situation in which errors occur provides an active learning environment. Error management training and stress inoculation training capitalize on that stress response, allowing learners to develop contingency plans, backup strategies, and stress management [36].

Benjamin Bloom's taxonomy of learning is a hierarchical classification of types of learning. Depicted as a pyramid, it implies that student abilities increase the higher on the pyramid they go, progressing from knowledge to comprehension, and then to application and analysis [37]. Knowledge, and comprehension are the simplest levels of learning. The ability of the learner to apply and analyze knowledge is an indicator of competence. SBT can facilitate advancing the learner from knowledge and comprehension to application, analysis, and even synthesis [34].

GHS preparedness is a complex and dynamic field involving the acquisition, retention, and rapid recall of large amounts of knowledge and the ability to quickly and precisely perform a variety of procedures. Procedural technical skills have traditionally been acquired through an informal manner exemplified by the mantra of "see one, do one, teach one". Reliance on chance exposure to procedural learning is suboptimal, especially for the GHS environment in which procedures are unplanned, unpredictable, and often time sensitive. Using simulation for high-stress psychomotor skills involves the steps of conceptualization: (1) the preparation to learn the procedure; (2) visualization of the procedure in its entirety performed by an expert; (3) verbalization and demonstration of the procedure with narration by the 
instructor of the steps being performed, breaking the procedure down into smaller task; (4) verbalization by the learner. During guided practice; (5) feedback. Watching video playback obtained with platforms such as tablets smart phones or point of view devices together provides a shared mental model which facilitates reception of feedback [38].

Extensive experience does not invariably lead people to become experts $[39,40]$. Coach Vince Lombardi coined the phrase "Practice does not make perfect. Perfect practice makes perfect." [41] Ericsson's theory of deliberate practice is defined as "a regimen of effortful activities designed to optimize improvement" and involves "training focused on improving particular tasks" [42]. Simulation enables learners to progress from just knowing information to being able to apply it in actual situations through deliberate practice. Some professionals develop faster than others and continue to improve during the ensuing years. These individuals are eventually recognized as experts. In contrast, many professionals reach a stable, average level performance within a relatively short timeframe and maintain this status for the rest of their careers. Expert performance requires continued deliberate practice for maintenance of high performance. Deliberate practice has been found to be key factor in maintaining expert levels as performers reach older ages. Most expert musicians have spent over $10,000 \mathrm{~h}$ of practice which is $5000 \mathrm{~h}$ more than less accomplished groups of musicians. A sufficient amount of weekly delivered practices been shown to allow expert pianists in their 50s and 60s to maintain their piano performances at a comparable level to that of young experts. Meta-analyses of the use and benefit of simulators in medical training have discussed the need for structured training and deliberate practice with the simulations guided by the goals of the training [43].

The learning curve theory applies to SBT. The learning curve is a logistic (S) shape of the relationship between time spent repetitive practice and improvement in performance and riches in an inflection point where learning becomes more effortful. A typical learning trajectory involves an initial latent phase, then rapid learning but later, after an inflection point, diminishing returns for each unit of effort invested. Each repetition results in an improvement in ability but there exists within a learning system some maximum learning achievable [44]. Environmental and emotional stressors may negatively affect critical thinking and clinical skill performance. By introducing more advanced simulation scenarios with added stressors, SBT facilitators may induce "stress inoculation" in learners and enable them develop responses to overcome stress-related performance barriers in high stress environments [40].

SBT should be based upon cognitive task analyses. The development of effective SBT requires a collaborative team effort where three types of expertise are coordinated: (1) specialty expertise focused on providing complete and accurate information about the critical skills and knowledge to be simulated; (2) instructional design expertise focused on the simulations and assessment methods that produce maximum learning and transfer of knowledge; (3) software development expertise for efficient design and development of the software required to capture expertise, presented in an engaging way, and assess student interactions with the simulator. 
The traditional teaching by subject matter experts often is inadequate due to unintentional omission of approximately $70 \%$ of critical decisions and analysis required to succeed for completing the task. It is critical to implement a collaborative team approach using cognitive task analysis methods, involving subject matter experts to produce complete and accurate representations of expert cognitive behavioral strategies. Cognitive task analysis-based strategies should be incorporated into the simulation authoring environment to guide the production of simulations for effective learning experiences [45].

Instructional design is a critical element of SBT. Simulation requires an instructional design framework to assist educators in creating appropriate simulation learning experiences. Simulation includes vastly different educational modalities. The framework for simulation instructional design has four domains:(1) Instructional medium; (2) simulation modality; (3) instructional method; (4) presentation. Each simulation modality is best suited for specific competency domains and learning outcomes. The choices within each domain are based on a matrix of simulation relating the severity of possible outcomes to the frequency of events, with a corresponding optimal "Zone of simulation matrix" [46].

Most learning does not take place during the simulation but rather during the debrief which should follow. A debriefing is a discussion that occurs immediately following the simulation experience during which educators and learners can reflect together, analyze performance and enhance the mental models that guide behavior. This reflection leads to permanent change [34]. Debriefing of learners after SBT session has been proposed as the primary learning method, with different models of debriefing depending upon the scenarios and knowledge level of learners [47]. Debriefing is a critical component of the simulation experience. Facilitators guide the students for the management of the scenario by discussing the learning objectives and providing feedback on the students performances. Key insights from SBT are derived during this important aspect [33].

\section{Blended Learning}

Blended learning is an integration of multi-media methods of instructional design that combines face-to-face instruction with online learning and simulation. Other words and phrases used to describe blended learning include web-based learning, e-learning, hybrid learning, flexible learning and mixed mode learning. Combining these alternative instructional methods with traditional instructional methods reconstitutes a "blended approach". Blended learning has been advocated to improve the preparedness training for the public health workforce [48]. A blended learning curriculum combining a standard course manual with simulation has demonstrated improved performance over a standard reading course [49].

Blended learning combines traditional instructor-led teaching and innovative technology-enhanced learning methods, reducing classroom seat-contact time 
[48]. Blended learning is a new term in the vocabulary of educators since the integration of computers and learning. Educators and information technology professionals refer to blended learning as those courses that combine face-to-face traditional classroom style teaching with online learning. Blended learning utilizing simulation has been shown to be effective in disaster medical education while improving faculty efficiency over traditional education methods. The blended learning approach is well received by learners and can offer significant enhancement to a online distance-based learning course, particularly when specific skills are required in addition to didactic information [50,51].

Blended learning and the "flipped classroom" model can be integrated with SBT and effectively teach preparedness for PHEICs to public health workers. Blending learning of online learning modules and on-site simulation has been effectively used for rapid deployment of EBV training. Virtual reality simulation presented on laptop computers coupled with human simulators has been proposed as a cost-effective method of hybrid SBT to achieve competency in train-the-trainer programs [48, 51, 52].

Prototypical blended learning programs for teaching disaster medicine consist of an e-learning platform with a classroom session involving problem-based learning activities, tabletop exercises, and a computerized simulation. The blended approach incorporating simulation tools successfully increased participants' disaster medicine competencies in performing mass casualty triage [50]. Students did have knowledge decay 6-12 months after course completion which is consistent with existing literature on decay of knowledge and skills following educational interventions [53].

Video-based learning also offers a promising alternative to traditional learning methods for teaching disaster medicine core competencies. Video modules have been shown to be as effective as traditional lecture teaching triage, decontamination, and personal protective equipment procedures. Recognizing that increased knowledge and comfort scores do not necessarily translate into task competencies, it was recommended that a practical skills demonstration component be added to the course for the testing of learners' practical skills and judgment [22].

Blended learning technologies also allow opportunities for unsupervised, selfregulated learning. Self-directed learning is when a learning environment is designed to promote autonomous learning. Studies suggest that directed self-regulated learning is as effective as instructor regulated learning yet allows more learner flexibility and access [54].

\section{Modes of Simulation}

There are multiple simulation technologies available to GHS educators, ranging from part-task trainers, computer-based interactive systems, computer-enhanced high-fidelity manikins, and virtual reality simulators [55]. Digitally-enhanced synthetic manikins vary technologically from high sophistication to low sophistication. Virtual workbenches use digitally generated images to create a medical training 
environment focused on specific skills with haptic feedback. Complex algorithms generate a virtual three-dimensional anatomy on a graphic display screen.

A partial task trainer is frequently the ideal tool if the learning objective is confidence and/or competence in an emergency procedure. The simulator can be as simple as an orange for learning injections to a virtual-reality ultrasonography model [29].

There are a number of terms used for the digitally-enhanced manikin modality, the most frequent of which are human patient simulators, high-fidelity simulators, and high-fidelity patient simulators. Although there are no strict definitions, these terms generally apply to full-body simulators with remote computerized controls, monitor displays of vital signs, and air compressor electrically- driven functions creating normal physiology and pathophysiological processes. High-fidelity manikins provide a suitable training platform for complex decision-making and integration of interventions into case-based scenarios.

Another technique for SBT utilizes screencasting. Screencasting is a type of lecture that incorporates digital recording of computer screen actions and audio narration. Screencasting can incorporate digital recording, narration, interactivity, and metrics into the lecture format. Assessment questions come embedded within the lectures to provide students immediate feedback on their understanding of the topic. Instructors can monitor students time spent viewing the lectures and their scores on embedded assessment questions to gain valuable pre-class assessment data [56].

Immersive simulation is a planned educational activity where learner or group of learners take part in the care of a simulated environment realistic enough for the participants to feel immersed in the surroundings, suspend disbelief, and manage the scenario as if it were real. There are numerous methods for creating immersive simulation. In situ simulation, where the scenario is executed in the actual work area such as the emergency department, intensive care unit, helicopter, or field response, can provide an equal experience and has its own advantages. Participants manage the simulated patient in their actual environments while performing tasks with their own equipment, allowing for increased realism, and enhanced transfer of the experience into actual clinical care [57]. Computer-based training is logistically simpler in most instances and as effective as more expensive forms of simulation. Successful applications of three-dimensional computer simulations include team training, clinical pathway management, and system-based simulations focusing on disaster response exercises for hospitals and prehospital events.

Digital learning is more effective when there is learner interactivity versus passive learning. Interactivity can be increased by using branched chain narrative virtual patient cases that require learners to actively participate in simulated clinical management [20, 58].

A simulation is considered live if all roles are played by human beings in a real environment with real systems. A training simulation is considered virtual if some roles, systems, and/or the environment is represented by a computer program, 
mathematically and/or graphically. A training simulation event is considered constructive if all the roles, systems, and environment are represented by a computer program. A combination of live, virtual, and constructive simulations has the potential to allow exploration of complex training scenarios alongside other environmental factors. An advantage of the combination includes being able to foster collaboration and trust under stressful medical situations. A disadvantage of live virtual constructive simulations is the cost [59].

\section{Simulation Fidelity}

The quality of simulation-based training experience depends on successful engagement with the learner. Achieving engagement depends on a sense of immersion, successful visuals, and simulator responsiveness. It is important for GHS educators to understand the implications of simulation fidelity on achieving learning objectives in order to determine what fidelity is optimal.

Simulation fidelity is how well the simulation represents reality. It is important that simulation technologies and fidelity be appropriately utilized and aligned with the learning objectives [60]. Simulations should have optimal fidelity to place learners in lifelike situations that provide immediate feedback about questions, decisions, and actions. Simulation fidelity consists of three distinct domains: engineering (physical equipment), environment, and functional [61]. Engineering is the degree to which the simulator replicates the physical characteristics of the actual task. This is usually directly proportional to the technological complexity and concomitant expense of the simulator. Environmental fidelity refers to visual, auditory, and other sensory feedback the simulator provides. Psychological fidelity is the degree of disbelief that learners perceive from the simulator and their interaction as if in an actual situation the simulator is emulating. Simulation fidelity is often, but not always, related to the level of simulator technology.

Healthcare simulation fidelity can also be expressed from Uwe Laucken's social endeavor perspective of three modes of reality- physical, semantical, and phenomenal. The physical mode are things that can be measured in standard physical measurement dimensions e.g., length, sound frequency, and weight. The semantical mode represents how presented information makes sense and can be logically interpreted. The phenomenal mode includes emotions and beliefs that learners experience during the simulation. The semantical and phenomenal modes represent psychological fidelity [62].

The concept of simulator fidelity usually implies the degree to which a simulator looks, feels, and act like a human patient. Although this can be a useful guide in designing simulators, this definition emphasizes technological advances in physical resemblance over principles of educational effectiveness. Studies have shown that the degree of fidelity appears to be independent of educational effectiveness. Several concepts associated with fidelity are more useful in explaining educational effectiveness, such as transfer of learning, learner engagement, and suspension of 
disbelief. It is been proposed to abandon the term fidelity in SBT and replace it with terms reflecting the underlying primary concepts of physical resemblance and functional task alignment, and shift from the current physical emphasis or emphasis on physical resemblance to a focus on functional correspondence between the simulator and applied context [63].

Simulations can achieve engagement with the learner more successfully if actions they perform in the scenario are followed by visible or audible responses. Human physiology can be simulated by various means including physiology engines, complex state machines (CSMs), simple state machines (SSMs), kinetic models, and static readouts.

Moderate fidelity approaches to simulate physiology are often managed by CSMs. CSMs are computer programs consisting of logical rules and decision treebased logic that responds to user activity. User actions, simulation timers, and other events trigger different states that change the patient presentation and vital signs. The major disadvantage of CSMs is that they do not respond well to unexpected, complex, or combinational inputs. Undesirable inputs and program complexity are addressed by limiting the variety of possible interventions. Recovery from user errors once a scenario is moved down a decision tree is difficult to program. VR and game-based simulations often use the CSM model.

Low fidelity approaches require less technology, effort, and sophistication to author. Patient simulations can use simple state machines to great effect. SSMs consist of three or more fixed states that alter the appearance, communication, and physiology data of the simulated patient. They lack branching and conditional features of the more complex CSMs yet still offer many of their benefits. They are especially useful in adding a dynamic appearance to a simple case presentation.

For many medical simulation-based educational experiences low fidelity approaches are often adequate if not preferable. Physiology engines are neither necessary nor desirable in many situations because simpler methods for depicting physiology states are often more practical. Physiology engines excel in advanced simulations and exploratory learning where sophisticated learners want to try unexpected things and see accurate responses. Examples of this include anesthesia and resuscitation simulations. CSMs are useful for interactive case scenarios in gamebased training because they provide predictable behavior, excellent responsiveness, and can be reasonably complex while appearing to have high fidelity. SSMs are wellsuited to interactive case scenarios, lecture presentations, and many activities because they're very easy to author yet are interactive and responsive to user input [64].

It is been proposed that the notion of high-fidelity versus low-fidelity simulation requiring complete technological replication of reality instead be replaced by accurate representation of real-world cues and stimuli. All aspects of fidelity significantly hinge on the learners perceived realism of the context of the learning episode as opposed to any one particular element [65]. The balance between costs and higher fidelity SBT depends upon the learning objectives and the learners' level of entering knowledge. The goal is to create an immersive environment which engages the 
learner. Low fidelity SBT is often as effective as high-fidelity SBT, and the task of the educator is to identify where the costs and learning curves meet [46].

Expensive, high fidelity simulators predict the real-world flight performance of expert pilots. There is an optimal point beyond which one additional unit of simulator fidelity results in a diminished rate of practical assessment of non-expert pilot performance. The total fidelity concept may be most appropriate for the training and assessment of expert pilots who can identify and process all the visual, aural, and other contextual cues of real-world aviation task. Novice pilots can become overwhelmed with total fidelity. This is because initially novice pilots must first familiarize themselves with the look, shape, location, and feel the actual devices in the cockpit and in the memorization and execution of emergency procedures. It can therefore be deduced that high fidelity is desired in simulation-based assessment devices that attempt to predicted expert performance in real-world situations. However, the same may not hold true for the practical assessment of learners with skill and experience level falling between novice an expert. With part task trainers, novice learners can build confidence and procedural knowledge, while enhancing safety and learning from mistakes [60].

There is ongoing debate on the effectiveness of training on live tissue models, such as goats, versus synthetic training simulation models. A study done by the United States Army showed that certain procedures were done as effectively on synthetic training models as on live tissue models. Some skills were done better on live tissue models, and studies are ongoing to evaluate new synthetic training models to replace live tissue training. Low fidelity models may be equivalent or better for novice trainees. It is difficult to predict which model might be best for training. Structural fidelity such as physical resemblance may be higher in one model such as a human patient simulator, and functional fidelity such as tissue feel enforces required may be higher in the live tissue model [66]. While learners may prefer life tissue training over simulation there is been no difference in performance between learners training simulators versus live tissue models [67]. There is also the cost of the life of an animal to consider and labor to prepare animal models which is increased over synthetic models [68]. Current initiatives in development of more realistic synthetic manikins include creating common open standards for hardware so the manufacturers and developers can create unique equipment tools which could be implemented on any manikin [69].

The effectiveness of simulation outweighs cost if human lives are at risk. Cost considerations, however objective and well-developed, should not be the sole concern. Funding decisions for simulation need to include personnel, facilities, equipment, materials, and simulation effectiveness [70]. Each one of these needs to be approached in the analysis, design, development, implementation, and evaluation for each of those domains [24]. 


\section{Virtual Reality}

Total immersion virtual reality (VR) is a progression from a virtual workbench that creates an all-encompassing virtual environment for the learner displayed in a threedimensional form. VR enables creating online virtual worlds with virtual patients which can be used for student assessments in clinical scenarios [71]. The display can be either on a computer screen or can be on a device worn by the learner. A 3-D virtual learning environment can demonstrate the interconnectedness of healthcare practices across disciplines. VR environments can utilize a technique called machinima, which is a method for making movies in the virtual worlds. Its realtime nature favors speed, cost saving, and flexibility over the higher quality of pre-rendered computer animation [72]. In full immersion virtual reality, the individual wears eye goggles that allow him or her to experience a normal enclosed spaces and interactive environment that he or she can move through and engage elements within, as if doing so in real life.

Scenarios requiring a physiologically responsive virtual patient require a modeling framework to build the virtual patient. This framework allows clinicians to remodel the patient physiology without requiring computer programming expertise. Virtual worlds are live, online, interactive three-dimensional environments in which users interact using speech or text by a personalized avatar. Access requires a modern computer and Internet connection. High fidelity environments can be prohibitively expensive for use on a large scale. The graphical fidelity of Second Life (C) and open simulators is sufficient to provide a realistic, immersive environment. Second Life, and the open source equivalent OpenSimulator, are low-cost, easily accessible virtual worlds [73].

Immersive training in a virtual environment has the potential to be a powerful tool to train GHS responders for high consequence, low frequency events such as a terrorist attack. The flexibility of the VR environment allows, with minimal programming effort, modifying avatars to simulate victims of unique hazards or injuries to emphasize specific skills [74]. Virtual training can be provided at flexible times and in modular components to test rare events. It can assess not only clinical skills, but also organizational proficiency-a key element of disaster management. It can be useful to cost-effectively meet various regulatory requirements and to provide sustainment in addition to initial training [75]. Simulation can be used to provide just-in-time training for critical care skills to responders who might not use them frequently enough to maintain their proficiency. Virtual simulators for GHS skills difficult to maintain, such as mechanical ventilation, have been developed. These skills will be essential during pandemics or emerging infectious diseases, which often require providers to extend their normal scope of practice into critical care skills [76].

Augmented reality is a combination of digital and physical media. Augmented reality adds computer-generated imagery to everyday objects to provide additional information about the object in the environment to a learner. An example of augmented reality is Body Explorer $($ C which uses a projector mounted above the patient simulator to provide $\mathrm{x}$-ray vision views of anatomy, physiology, and clinical 
procedures. Microsoft HoloLens $(\mathcal{C}$ is a mixed reality head-mounted device. The see-through holographic computer allows one to view high-definition holograms within his or her learning space. Working in the virtual environment allows learners to experience a realistic work situation, explore information and action options, and receive feedback from the virtual patient as they proceed. VR systems can shorten the learning curve, decrease practice time, and improve learning outcomes [77].

Training healthcare teams in online, virtual environments with dynamic virtual patients is an effective method of training for management of mass casualty incidents. Live exercises are the accepted "gold standard" for healthcare disaster exercises, but they are costly and time-consuming to organize, and may be disruptive to local services. These drills are expensive to provide and require abundant resources, including volunteers to play patients, moulage artists, and participation by many healthcare and safety personnel, taking instructors and trainees away from their normal duties for extended periods of time. Despite the cost and disruption of organizing and running major incident exercises there is little evidence of their effectiveness in improving the preparedness of an organization for a major incident response. Low-cost virtual worlds have been successfully developed and tested for preparation and training multiagency and multisite major incident responses. Virtual environments are more immersive over tabletop exercises, placing participants into a realistic and stressful environment which can be based upon their local or novel surroundings. Scenarios can be reset rerun within seconds to maximize the resource availability and cost effectiveness, enabling participants to perform and gain an understanding of multiple key roles. The ability to record and playback the scenarios from a point of view of each participant enables accurate and structured debriefing, either by expert facilitators or peers, which is difficult to achieve in a large-scale live or tabletop exercise. Virtual worlds also have the advantage of replicating exactly out location resources in a healthcare facility. Trainees do not have to be present at the same location to play their avatar roles, drills can be conducted at any time of day or night; a variety of patient conditions remodeled to simulate the complexity of a real mass casualty incident, even deaths. Scenarios can be run more than once in a short period of time allowing trainees to learn from their mistakes; and trainees performance during the simulation recapture for playback and assessment after the after the event $[73,78]$.

VR simulation has been shown to be equivalent to live simulation with standardized patients in assessing mass casualty triage skills, including identifying and treating bioterrorism diseases [75, 79-82] In a dynamic VR learning environment, each victim can be triaged multiple times, first in primary triage and again in a secondary triage area. This enables users to test their knowledge in a wide range of victim scenarios and receive immediate feedback [83]. Novice learners have demonstrated improved triage and mass casualty intervention scores, speed, and selfefficacy during an iterative, fully immersed virtual reality experience [84].

Team training with online virtual world simulation yields comparable results as are achieved with the traditional method for simulation-based team training with instrumented manikin- based simulation and a real physical environment. VR scenarios can be presented to multiple trainees simultaneously over time to geographically dispersed locations, reducing costs [85]. 
VR provides flexible, consistent, on-demand training options. VR is an effective training platform for rare GHS incidents where high level performance is critical, but difficult to rehearse, such as CBRNE incidents [81]. A VR hybrid approach has been successfully used to simulate Ebola treatment centers. By immersion in a highly realistic Ebola treatment center projected on the wall, learners advance to accomplish competency-based specific operational skills by using real equipment and performing procedures on manikins. This hybrid simulation model provides trainees opportunities to integrate different evaluation methodologies, such as using fluorescent liquid or powder under ultraviolet light to measure the degree of exposure, and video cameras for education replay and educational analysis [86].

VR has the ability to record and assess patient flow aspects of the simulated mass casualty incident response, from individual patient movements to overall nontechnical and team performance. The visual layout can be customized to match actual hospitals to prepare local staff or site-specific responses or scenarios. The virtual healthcare facility allows learners to recognize the need to prioritize the availability of "downstream" beds with higher levels of care in intensive care units versus focusing primarily on the "upstream" management of acutely presenting patients, and actions can be recorded, replaced, and reflected upon [87]. VR simulations are effective in identification of bottlenecks, crowd control issues, and resource needs to educate key hospital decision-makers about disaster procedures prior to a full-scale drill [88].

Individual GHS skills can be assessed in online 3-D virtual world simulations using virtual patients. Commercial software such as Second Life(C), a 3-D virtual accessible via the Internet can be used to provide simulations. Learners are able to navigate through the virtual world and manage a virtual patient via an avatar, an online character. The inherent benefits of 3-D virtual patients can be extended to every GHS specialty that encompasses patient contact [71].

Computer-based virtual patients are not being utilized to create high fidelity simulated patient interactions. The term virtual patient is used to represent a variety of developing technologies to create interactive computer models of the patientprovider interaction, simulating communication and information gathering, and allowing the user to apply diagnostic reasoning. Computer-based virtual patients can be integrated into GHS curricula in a flexible manner. The most efficient use of these cases is for institutions to exchange, edit and reuse them, and create a pool of cases for general use. To overcome these challenges a virtual patient working group was established by MedBiquitous, a nonprofit organization accredited by the American National Standards Institute to develop information technology standards for VR patients $[20,58]$.

VR can also incorporate adaptive educational technologies. Learners vary greatly in knowledge and a one size for all approach is insufficient. Adaptive educational technologies can address learning challenges presented by complex learning performance environments such as GHS, and can minimize the amount of time in which advanced learners are bored and struggling learners are overwhelmed. Adaptive learning technologies include software that can partially mimic a simulation educator to meet immediate and long-term needs of leaners learners with minimal or no human intervention [89]. 


\section{Simulation Applications in Health Security Exercises}

Simulation exercises are an essential component of GHS emergency preparedness and response. While training is essential, responders need the ability to practice what they've been taught in order to build their confidence to be able to apply those skills in the event of an emergency. The Homeland Security Exercise and Evaluation Program (HSEEP) provides a set of guiding principles for exercise programs as well as a common approach to exercises $[90,91]$. The WHO recommends nations include simulation exercises in monitoring and evaluation to test the actual functionality of their required International Health Regulations (IHR) core capacity and share lessons and best practices with other countries and stakeholders. Protocols for national simulation exercises include table-top exercises, skill drills, national functional assessment exercises, or full-scale exercises, which may be combined. Simulation exercises have been identified as a key component in the validation of core capacities under the IHR monitoring and evaluation framework. They play a key role in identifying the strengths and gaps in the development and implementation of preparedness and response measures [68, 92, 93].

Functional exercises represent an important link between disaster planning and disaster response. Although these exercises are widely performed, no standardized method exist for their evaluation. Conducting a functional exercise requires extensive preparation, and large amounts of time and money are often required. The effectiveness of standard disaster drills as a tool for hospital preparedness is difficult to determine due to the logistical challenges of conducting these exercises and their effect on normal healthcare operations [94].

Simulations have been shown to have equivalent results compared with live standardized patients. Participants rated simulators equivalent with respect to realism, disease representation, physical examination findings, and administering treatments. Simulators also offer the advantage of less variability than live actor patients in case presentation and progression [95]. Interactive screen-based simulation is potentially easier and more convenient to accomplish with computerized mass casualty scenarios than having live moralized standardized patients for mass casualty incident drills. Computerized simulations did not have the psychological fidelity of standardized patient drills and functional fidelity. The ability of the simulation to portray realistic inputs and outputs by the participant is important [96]. To maximize the benefit of these exercises, accurate evaluation of the actions carried out during the exercise is necessary [97]. Computerized simulations have ability to include built-in evaluations and debriefing.

Most clinical personnel are unfamiliar with the complex processes, equipment, and unwavering attention to the small but necessary details associated with low-frequency, high-consequence GHS events. An advantage of simulation is a re-creation of a safe and realistic environment where trainees can gain and maintain essential skills. Simulations may include practice with the use of cognitive aids and checklists. Simulation may also be used for testing and validating action protocols before actual implementation and the actual context of care [98]. Internetdistributable training programs that provide course materials and built-in evaluation 
tools to train healthcare workers in high risk infectious disease responses, such as EVD, are available. Courses include an online self-study component, a hands-on simulation workshop, and a data driven performance assessment toolset to provide debriefing [99]. The U.S. military has recognized that simulation training is an integral component for EID outbreak preparedness, and created a program of instruction outlining a formalized EVD training program using high fidelity simulation replicating the work environment inside an Ebola treatment unit [100].

Multidisciplinary simulations have demonstrated gaps in systems that could expose responders to EVD. Walk-through evaluations do not provide information on latent threats at the same level of granularity as a full-scale simulation. Improvements may not be accomplished with a "one and done" simulation experience, and longer periods for deeper simulations may be required. This type of effort is not possible without an investment in simulation educators, technologists, and a robust simulation infrastructure [101].

Simulations integrating video recording of provider behavior can be used to assess the effectiveness of PPE techniques. Ultraviolet tracers, liquids that fluoresce under ultraviolet light, can be used to simulate provider self-contamination while doffing PPE. The UV tracer is a useful analog of contaminated bodily fluids because it spreads easily and its spread decreased with the use of barrier methods. This model can be used during simulations to measure the effectiveness of different forms of PPE and provider competencies for appropriately donning and doffing PPE [102]. Video recording of simulations have been used to identify PPE errors for failure modes and effects analyses. Human factors methodologies can identify errorprone steps, delineate the relationship between errors in self contamination, and suggest remediation strategies. Simulations can assist in probing processes to identify latent system hazards and human factor effects [29, 76, 103].

Simulation can be used to teach teamwork for multiple patient casualty scenarios. Teamwork is a critical aspect in response to multiple patient casualties. Team situational awareness, team leadership, coordination, and information exchange are core team processes required for team performance and multiple patient casualty scenarios. Relevant behaviors and sub-behaviors within these processes can be observed in simulations [104].

\section{Game-Based Learning Health Security Applications}

The benefits of simulation are well documented, however the significant expense in human resources required to deliver traditional manikin or standardized patient simulations have resulted in questions on whether such resource intensive modalities are needed. Game-based learning (GBL), which falls under the umbrella of simulation, is poised to take on a greater role in GHS training. As the number of serious games for healthcare training continues to grow, having schemas that organize how educators approach their development and evaluation is essential [105]. 
GBL is a disruptive technology that sits at the intersection of high-fidelity simulation, computer-based learning, and distance education [106]. Games with the purpose of improving an individual's knowledge, skills, and attitudes are called serious games [107]. Similar to aviation simulators which train pilots in emergency procedures, serious games have been used to train surgeons in situational awareness for addressing crises and their ability to anticipate nonroutine adverse events during surgery [108A]. Serious games have been used to train forward combat casualty care medical personnel in a hostile remote environment advanced lifesaving procedures and trauma triage to non-trauma specialists [109-111].

Games should be used for targeted learning objectives, and should align with classroom activities, and not confuse liking with learning [112]. Educational game design and development is a process of defining learning and assessment goals, determining what is needed to achieve those goals, developing an appropriate simulation, and validating its effectiveness. The methodology often used is the ADDIE instructional design model of analysis, design, development, improvement, and evaluate. Portions of the methodology may require a compromise between educators and developers because instruction and assessment requirements may dictate selection of a particular genre platform. Learning outcomes from simulations also depend how well the domain instruction is integrated into the simulation due to cognitive load theory. Cognitive load is the total amount of mental activity imposed on working memory at a point in time. Extraneous cognitive load is a load caused by any unnecessary stimuli. These are key design considerations when designing educational games [113]. Achieving the proper balance between entertainment and instruction in a game is essential and can be difficult to attain. Serious games are an experiential activity, rather than a presentation requiring memorization of facts. Learning goals and gameplay are often not disclosed to the user. Often the user learns by playing the game, where discovery in itself may be part of the gameplay [114].

GBL simulations have the interactivity of high-fidelity simulation with the added benefits of convenience, scalability, and easy distribution. An important concept in game-based learning is the concept of flow. A common colloquialism for this concept is "being in the zone". Flow is a mental state in which the person is fully engaged, focused, and committed to the success of the activity. Inducing a flow state is a key goal in game-based learning. A learner cannot consciously force themselves into a flow state, but three conditions make flow more likely: (1) the learner must be immersed in an activity which the goals are clearly stated; (2) the learner must believe they possess the skills to overcome the perceived challenge; (3) the task must include prompting coherent feedback allowing learned to adjust their performance to accommodate changing demands [106].

Every learner decision in a game can be exported to a learning management system. This ability to track assist learners to assess their own progress, and can used both for formative and summative assessment. GBL utilizes the concept of chaining. Chaining is an instructional concept attributed to B.F. Skinner. Chaining is achieved by breaking down complex behavior of the multiple individual behaviors called links. Each link must be mastered before moving onto the next, and each link 
reinforces the behaviors mastered before it. This is also known as laddering or scaffolding. GBL uses this to teach complex tasks through small interwoven, interactive links [106].

The development of learning games is complex. Game development requires expertise in GHS, education, and technology development to create the complex design, modeling, and scoring required to make an effective game. Game development can be costly and require lengthy development time. Proposed frameworks for game development have been proposed using a three-phase development process. The first phase is preparation and design. This includes identifying and funding the appropriate members needed to develop the technical components i.e. game developers, GHS content subject matter experts, and users. A development schedule to include frequent meeting should be agreed upon. The second component in this phase is a subject matter concepts transfer. The SMEs demonstrate how to perform tasks, allowing game developers to ask questions and take notes and photographs for reference. One of the key challenges in game development is difficulty conveying expert concepts to nonexpert developers. Concepts transfer helps orient the game developers to the information to be shared or used in the game. Content production, including any necessary physiological modeling incorporating existing evidence, guidelines, and expert derived algorithms is completed during this phase with storyboards describing the flow and required functionality of the game. The second phase is development of wireframes, which are illustrations of proposed game components and assist in visual communication design of the structure, functionality, and learner interface. The third phase is a formative evaluation. This starts with usability testing to identify content, design, functionality, and usability problems with the game, and should include both subject matter experts and end-users. After usability testing is complete and all edits have been made, the final product is delivered for beta testing [115].

Before GHS educators consider using serious games as solutions for GHS competencies, it is important to understand that the problem is being addressed by the game and that a proposed claim of effectiveness is indeed trustworthy. The functionality of a serious game differs from that of a mobile health application. Mobile health applications communicate information where as a game requires the user to operate or interact with the content, with the ultimate goal to change one's behavior in real life, i.e. learning [108].

\section{Distributed Telesimulation}

Distributed simulation is a method to increase GHS access to SBT worldwide. Distributed simulation is providing SBT over the Internet, utilizing real-time videoconferencing or asynchronous computer-based virtual reality. Distributed simulation can increase access to SBT and to provide just-in-time training to the learners at the right time and place [116]. Training effectiveness of simulation by remote facilitation is as effective as traditional locally facilitated simulation. Remote simulation can 
be a viable alternative method, especially where experienced SBT facilitators are limited [117].

SBT can be delivered electronically to remote areas far from the simulation center faculty that cannot logistically support their own local simulation program, either because of space, simulators, or staff. Simulation distributed from a central location can be provided asynchronously to other facilities regardless of time zone differences, facilitating participation when learner schedules allow. Distributed simulation can provide SBT to GHS responders who do not have adequately-resourced simulation programs or the additional capacity to provide required training for new programs [50]. The concept of distance-based simulation training is based on remote access to the central simulation facility and its patient simulator from any number of distant training sites located anywhere that has adequate communications, or alternatively having the patient simulator located at a distant site with learners and connected to a central simulation faculty site. SBT can be conducted under the guidance of an expert teacher physically present at the central simulation facility [118].

High-frequency, low-fidelity distributed simulation has been used to prepare health-care workers on EBV personal protective equipment using virtual reality in a "fragile health system" and low literacy levels in Liberia. This project utilized lightweight laptop computers and off-the-shelf (OTS) software to create a virtual reality immersive and an interactive clinical environment [39]. The American College of Surgeons Advanced Trauma Life Support course has been effectively taught by distance learning, including the skills station components of the course. For troubleshooting, quality control, and for assisting with the skills teaching there should be faculty at the remote course site [119].

Three domains of successful SBT applications in resource limited global health applications have been described. The first is the ability to provide academic affiliations to academically trained clinicians in remote areas. Secondly, SBT can provide mastery-based instruction to those who otherwise would not have access to it. Thirdly, it can develop partnerships between community-based traditional healers and professional health-care workers [120].

Distributed simulation enables deployment of GHS "train the trainers" programs to remote areas. This model has the advantage of overcoming cultural barriers to instruction and can lead to providing a lasting GHS training infrastructure in the region. There are many benefits to the model. These programs leverage limited resources to create sustainable educational systems, which are the central part of developing a public health system. Once a cadre of experienced educators is created in the host country, education can proceed in an exponential fashion with proper ongoing support. Another benefit of this model is a consultant trainers do not need to uproot themselves from the home country, which could be disruptive to their careers and family. Working with their host to develop curricula allows the idiosyncrasies of local practice to be incorporated into the curriculum. It is suggested that trainers first develop their courses alongside their sponsors, then practice administering the 
course together, and finally deliver the course with the consultants present only in a supportive role which can be done through remote simulation [94].

Distance-based distributed simulation integrates multiple innovative technologyenhanced learning (TEL) concepts, particularly telepresence, focused on digitally distributed simulation to remote locations. Telepresence is the experience of being fully present at a live real world location remote from one's own physical location. TEL can establish telepresence by various means. The telepresence established by distance-based distributed simulation facilitates students from different sites being able to learn vicariously through observation of the simulation at another site. Vicarious learning by observers and remote debriefing can increase the number of learners per SBT session and increase remotely delivered SBT utilization. Vicarious learning has been demonstrated to be an effective as direct learning if augmented with observation scripts provided to the learners. Observation scripts focus learners' attention on important objectives of the simulation and can improve peer feedback [121].

There are logistical and pedagogical challenges to providing SBT in resourceconstrained areas. Limited technology infrastructures may limit SBT to low-fidelity simulators. Simulation should be combined with hands-on learning, particularly for psychomotor skills. Care must be taken to ensure that SBT is aligned with local cultural norms and is respectful of local health-care customs and traditions, including recognizing that roles of different professionals may vary, particularly roles of-nontraditional healers, and uses of different medications and therapies [122, 123],

Remote facilitated simulation-based learning is technically feasible with low-cost, pre-existing, and easy access resources. This can be applied to any simulators driven by personal computer. A remote facilitator can control the simulator and provide simulation training and debriefing to trainees. This type of approach can enable novice facilitators to learn how experienced facilitators run sessions and debrief remotely. These applications can enhance dissemination of SBT and globalization of training efficiently, leading to standardization of patient care [124]. Distributed simulation can be enhanced by integrating application sharing software into simulations [125]. Having learners utilize GHS-related desktop or mobile applications that are demonstrated and screen-shared by remote facilitators can reinforce their use.

Simulation-based medical education may be difficult to adopt in developing countries because it requires expensive equipment, adequate facilities, and experienced staff members. Challenges to overcome simulation-based training in developing countries may include difficulty in transporting high-technology equipment and solving equipment problems that occur on site without communications to technical assistance [126]. Distributed simulation facilitators should be well prepared and utilize a checklist for simulation related activities to prepare both the broadcast and the learner remote sites and also utilize a script for instructing local and remote learners on the expectations of the simulation [127].

A potential barrier to expanding SBT is the availability of qualified SBT instructors. Allowing instructors to remotely observe and debrief simulation sessions can make simulation-based instruction more convenient, thus expanding the pool of 
instructors available. The debriefing instructor can be remote from the actual simulation and still provide real-time feedback and discussion on the performance of learners [128].

Instructors may face challenges to master the technology and achieve a telepresence with learners [129]. Remotely facilitated simulation can be optimized through short training sessions for remote learners on the technical aspects, such as camera and audio equipment familiarization. It has been recommended that a prior face-to-face meeting may enable nonverbal cues to be recognized during subsequent teleconferencing and helps to clarify visual and social cues [130].

Learners in remotely facilitated simulation-based training have reported feeling uncomfortable without instructors present, that communication was a barrier to learning, and that the quality of instruction was inferior. Learners may be willing to overlook remote facilitated simulation-based training deficiencies because these were outweighed by perceived benefits of having access to simulation-based training versus not having access at all. Although learners may consider remote facilitation simulation experiences less positive than locally facilitated it has not shown to have a measurable impact on knowledge or learning outcomes [131].

As in live SBT, an integral component of distributed simulation is debriefing, during which learning and reflection are greatest. To be maximally effective, debriefing should be performed by facilitators who have both experience in the subject matter and have a strong understanding of debriefing principles. Qualified instructors to facilitate post-simulation debriefing may be inadequate in remote locations, resulting in suboptimal educational experiences for learners. By connecting SBT educators from geographically distant areas, learners are exposed to faculty who can provide content expertise and high-quality debriefing [132].

Distributed simulation has the ability to be integrated into existing telemedicine systems and vice versa. This would accomplish dual purposes of training and providing real-time or asynchronous mentoring and consultations with higher level care facilities. Remote telemedicine consultations to minimally-trained providers in resource-constrained situations has been demonstrated to be effective [133]. Coupling these two technologies can be synergistic for GHS preparedness.

\section{Modeling and Simulation for Global Health Security Preparedness}

As computing resources become more affordable and modeling and simulation capabilities become more advanced, modeling and simulation offer greater far-reaching benefits to support GHS training and decision making. Although the terms modeling and simulation are often used interchangeably, they are distinct terms. Modeling is a representation of an object or phenomena, which is used by simulation. Models are mathematical, physical, or logical representations of a system, entity, phenomena, or process. Models are used by simulation to predict 
the future state. Simulation is a representation of the functioning of a system or process. Through simulation, a model may be implemented with unlimited variations, producing complex scenarios. These capabilities allow analysis and understanding of how individual elements interact can affect the simulated GHS environment.

Modeling and simulation can provide rehearsal environments for GHS responder personnel. Modeling and simulation can answer "what if" questions and provide an experimentation or training environment that may not otherwise be realized.

Models and simulations are set up to locate the peaks and valleys and performance envelopes, so systems can be optimized prior to development. Dynamic GHS events, such as pandemics, mass casualty events, or pandemics challenge GHS decision-makers with uncertainty, complexity, and rapid change. Modeling and simulation virtual environments allow learners to interact with the virtual environments to test hypotheses, such as analyzing acute disease epidemiology by investigating a disease outbreak in a virtual community. Modeling the simulation offers great potential to inform thinking by enabling the examination of complex problems [134].

Modeling can be used to assist in GHS, such as mass care after a disaster. Predicting patient load in mass gatherings is a nonlinear problem, with a nonlinear relationship between patient presentations and multiple event characteristics. There is a positive correlation between environmental factors. Modeling can be useful for predicting patient presentation numbers not only for planned mass gatherings but for unplanned mass security events [135].

Modeling has been used to assist hospitals in planning for surge operations during a future influenza pandemic. Models allow for changes in the length of stay, ventilator usage, and the attack rate of the virus. The Centers for Disease Control and Prevention (CDC) developed FluSurge to estimate daily demands of patients and resource use for a flu epidemic [136]. FluSurge is available as a downloadable Excel spreadsheet online. A software tool, the Hospital Surge Evaluation Tool, was recently developed by the U.S. Department of Health and Human Services to support live surge capacity drills and tabletop exercises [137].

Modeling has also been used to predict disaster responses for 25 major US cities using a hybrid of geographic information systems and dynamic modeling. The Disaster Response Simulation Model provides emergency preparedness and health systems planners more realistic estimates for mass casualty events. It identified longer wait and transport times needed to distribute high numbers of patients to distant trauma centers in sudden-impact disasters, which created predictable increases in mortality and trauma center resource utilization [137].

Modeling and simulation can be used to assess and enhance hospital surge capacity [139]. It is recommended that emergency planners collaborate with human factors and industrial engineers who are experts in risk analysis, modeling, and systems analysis. Individual hospitals may assess their surge capacity and flow constraints by using analytic tools or computational modeling to examine patient flow analysis, staff utilization efficiencies, hospital bed the man patterns, throughput, and wait times [140]. Different strategies to expand hospital surge capacity, such as 
opening unlicensed beds, canceling elective admissions, and implementing reverse triage can be interactively evaluated [141]. Computer simulation modeling to assess the effect on emergency department length of stay of increasing the number emergency department beds versus altering the admitted patient departures from the ED has been used to find the optimum patient flow interventions [142].

Modeling has been combined with statistical process control methods to visualize opportunities to improve surge capacity during a mass casualty incident. Modeling can allow a reproducible and reusable instrument to measure surge capacity. A standardized simulation scenario can be used to develop baseline metrics in a simulation repeated under various conditions to quantify the relative changes in surge capacity [143]. Modeling has been used to incorporate human movement trajectory data during triage drills by tracking patient movement and providing data for optimization of use of limited spatial resources within a triage post [144].

Discrete event simulations are widely used to model a number of healthcare settings and successfully assess patient flows. The benefits of discrete event modeling to iteratively design and test technologies and work processes, such as an electronic patient tracking system, allows assessment of human performance measures before they are implemented. Unexpected consequences may ensue from these technological solutions that they failed to provide support for providers work activities and have negative consequences on performance and potential patient safety [145]. Discrete event modeling is applicable to GHS contingency planning, such as deployable field hospitals and EVD treatment centers.

Before using a simulation to draw conclusions or provide recommendations, it is necessary to build the blocks of the modeled process, flows, resources, and constraints, acquire accurate figures for input to the system, and validate the model against empirical evidence. Professional versions of such software can have prohibitive purchasing or licensing costs and require significant internal or consulting resources to program, test, and produce accurate estimates. Spreadsheet simulations have been explored for simulation modeling and are nearly as effective as traditional simulations but easier to use, understand, and implement. Spreadsheet software is widely available at a fraction of the cost of discrete event simulation software [146].

Accurate modeling requires data, and data on GHS events can be challenging to obtain. To fill this gap GHS planners can leverage military medical data collection and modeling and simulation efforts. The U.S. Department of Defense has collected data on wounds, diseases, treatments and patient outcomes in military conflicts since 2004. This data makes up part of the Joint Theater Trauma Registry and includes similar data collected by other military branches. It is been proposed to combine this data with nonmilitary data such as from the National Trauma Databank to develop a modeling and simulation databank for medical disaster responses, including primary care for illnesses that may or may not be directly related to the disaster itself. However, rigorous long-term efforts must be made to collect disaster response patient care data during GHS events, including the number and types of injuries and illnesses seen by responders. Empirically-based modeling and simulation can help GHS disaster planners be prepared for the infrequent but "Predictable surprise" [147, 148]. 


\section{Conclusion}

SBT and modeling have the potential to be GHS workforce multipliers by reaching out to responders who have limited access to training. SBT has demonstrated its effectiveness and positive return on investment. Challenges with initial front-end funding remain. An adequate Internet infrastructure is required to effectively utilize remote distributed SBT, which may limit SBT deployment in resource-constrained regions. New technologies continue to increase Internet coverage in developing countries and improved bandwidth in developed countries. Instructional designers and serious game developers are continuing to decrease the need for high-speed networks while simultaneously mobile device manufacturers are increasing the processing speeds and memory of mobile devices.

GHS educators need to learn how to leverage SBT technologies to reach the public health workforce. GHS educators also will need to collaborate with software developers and instructional designers to ensure that the goals of increasing public health workers' competencies are achieved by aligning SBT fidelity with learner objectives.

SBT is a tool, not a technology, and simulation faculty and facilitators need to be familiar with the principles of simulation education, particularly learner immersion and debriefing skills. GHS leaders should prioritize obtaining funding support for increased SBT deployment to address the public health workforce shortages and capability gaps.

\section{References}

1. Green MS et al (2018) Confronting the threat of bioterrorism: realities, challenges, and defensive strategies. Lancet

2. Gardner AK et al (2016) Using simulation for disaster preparedness. Surgery 160(3):565-570

3. Executive order - advancing the global health security agenda to achieve a world safe and secure from infectious disease Threats. 2014

4. Global Health Workforce Alliance (2015) A universal truth: no health without a workforce. World Health Organization, Geneva

5. Heymann DL, Takema LC, Fidler DP, Tappero JW, Thomas MJ, Frieden TR, Yach D, Nishtar S, Kalache A, Olliaro PL, Torreele E, Gostin LO, Ndomondo-Sigonda M, Carpenter D, Rushton S, Lillywhite L, Devkota B, Koser K, Yates R, Dhillon RS, Rannan-Eliya RP (2015) Global health security: the wider lessons from the West African Ebola virus disease epidemic. Lancet 385:1884-1901

6. Haussig JM et al (2017) The European Medical Corps: first public health team mission and future perspectives. Eur Surveill 22(37):1-6

7. U.S. Department of Health and Human Services (2016) Report of the Independent Panel on the U.S. Department of Health and Human Services (HHS) Ebola Response, Retrieved from https://www.phe.gov/preparedness/responders/ebola/ebolaresponsereport/documents/ebolapanel.pdf 
8. Global health security agenda: getting ahead of the curve on epidemic threats. Testimony of Dr. Rajiv Shah, USAID Administrator, before the House Committee on Foreign Affairs, in House Committee on Foreign Affairs

9. Global Burden of Disease 2017 Sustainable Development Goals Collaborators (2018)

10. Sands P, Mundaca-Shah C, Dzau VJ (2016) The neglegted dimension of global security - a framework for countering infectious-disease crises. N Engl J Med 374(13):1281-1287

11. Nuzzo JB, Cicero AJ, Inglesby TV (2017) The importance of continued US investment to sustain momentum toward global health security. J Am Med Assoc 318(24):2423-2424

12. Burkle FM (2016) The World Health Organization global health emergency workforce: what role will the United States play? vol 10. Disaster Medicine and Public Health Preparedness, Preparedness, pp 531-535. https://doi.org/10.1017/dmp.2016.114

13. Daily E, Padjen P, Birnbaum M (2010) A review of competencies developed for disaster healthcare providers; limitations of current processes and applicability. Prehosp Disaster Med 25(5):387-395

14. Amat Camacho N, Burkle FM, Ingrassia PL, Ragazzoni L, Redmond A, Norton I, von Schreeb J (2016) Education and training of emergency medical teams: recommendations for a global operational learning framework. PLOS Curr Disasters. https://doi.org/10.1371/ currents.dis.292033689209611ad5e4a7a3e61520d0

15. Evans DP et al (2016) Innovation in graduate education for health professionals in humanitarian emergencies. Prehosp Disaster Med 31(5):532-538

16. Hansoti B, Kellog DS, Aberle SJ, Broccoli MC, Feden J, French A et al (2016) Preparing emergency physicians for acute disaster response: a review of current training opportunities in the U.S. Prehospital Disaster Med 31(6):1-5. https://doi.org/10.1017/ S1049023X16000820

17. Koenig KL, Tsai SH (2011) Crisis standards of care: refocusing health care goals during catastrophic disasters and emergencies. J Exp Clin Med 3(4):159-165

18. Noguchi N, Inoue S, Shimanoe C, Shibayama K, Matsunaga H, Tanaka S, Ishibashi A, Shinchi K (2016) What kinds of skills are necessary for physicians involved in international disaster response? Prehosp Disaster Med 31(4):397-406

19. Subbarao I, Lyznicki JM, Hsu EB, Gebbie KM, Markenson D, Barzansky B, Armstrong JH, Cassimatis EG, Coule P, Dallas C, King R, Rubinson L, Sattin R, Swienton R, Lillibridge S, Burkle FM, Schwartz RB, James JJ (2008) A consensus-based educational framework and competency set for the discipline of disaster medicine and public health preparedness. Disaster Med Public Health Prep 2:57-68

20. Triola M, Feldman H, Kalet A, Zabar S, Kachur E, Gillespie C, Anderson A, Griesser C, Lipkin M (2006) A randomized trial of teaching clinical skills using virtual and live standardized patients. J Gen Intern Med 21(5):424-429

21. Markenson D, Dimaggio C, Redlener I (2005) Preparing health professions students for terrorism, disaster, and public health emergencies: core competencies. Acad Med 80(6):517-526

22. Curtis HA, Trang K, Chason KW, Biddinger PD (2018) Video-based learning versus traditional lecture for instructing emergency medicine residents in disaster medicine principles of mass triage, decontamination, and personal protective equipment. Prehosp Disaster Med 33(1):7-12. https://doi.org/10.1017/S1049023X1700718X

23. Issenberg SB, McGaghie WC, Petrusa ER, Gordon DL, Scalese RJ (2005) Features and uses of high-fidelity medical simulations that lead to effective learning: a BEME systematic review. Med Teach 27(1):10-28. https://doi.org/10.1080/01421590500046924

24. Fletcher JD, Wind AP (2013) Cost considerations in using simulations for medical training. Mil Med 178(October Supplement):37-46. https://doi.org/10.7205/MILMED-D-13-00258

25. Friedl KE, O'Neil HF (2013) Designing and using computer simulations in medical education and training: an introduction. Mil Med 178:1-6

26. Ziv A, Wolpe PR, Small SD (2003) Simulation-based medical education: an ethical imperative. Acad Med 78(8):783-788 
27. Gaba DM (2004) The future vision of simulation in health care. Qual Saf Health Care 13(Suppl 1):i2-i10

28. Subbarao I, Bond WF, Johnson C (2006) Using innovative simulation modalities for civilian-based, chemical, biological, radiological, nuclear, and explosive training in the acute management of terrorist victims: a pilot study. Prehosp Disaster Med 21(4):272-275

29. Ten Eyck RP (2011) Simulation in emergency medicine training. Pediatr Emerg Care 27(4):333-344

30. Cook DB, Hatala R, Brydges R, Zendejas B, Szostek JH, Wang A, Erwin PJ, Hamstra SJ (2011) Technology-enhanced simulation for health professions education: a systematic review and meta-analysis. J Am Med Assoc 306(9):978-988

31. Elcin M, Onan A, Odabasi O, Saylam M, Ilhan H, Kockaya PD, Gurcuoglu I, Uckuyu Y, Cengiz D, Nacar OA (2016) Developing a simulation-based training program for the prehospital professionals and students on the management of middle east respiratory syndrome. Simul Healthc 11(6):394-403. https://doi.org/10.1097/SIH.0000000000000198

32. McGaghie WC, Issenberg SB, Barsuk JH, Wayne DB (2014) A critical review of simulationbased mastery learning with translational outcomes. Med Educ 48:375-385. https://doi.org/ $10.1111 /$ medu. 12391

33. Wang EE (2011) Simulation and adult learning. Dis Mon 57:664-668. https://doi.org/10. 1016/j.disamonth.2011.08.017

34. Zigmont JJ, Kappus LJ, Sudikoff SN (2011) Theoretical foundations of learning through simulation. Semin Perinatol 35:47-51. https://doi.org/10.1053/j.semperi.2011.01.002

35. McGaghie WC, Harris IB (2018) Learning theory foundations of simulation-based mastery learning. Simul Healthc 13(3S):S15-S20. https://doi.org/10.1097/SIH.0000000000000279

36. Hughes PG, Crespo M, Maier T, Whitman A, Ahmed R (2016) Ten tips for maximizing the effectiveness of emergency medicine procedure laboratories. J Am Osteopath Assoc 116:384-390. https://doi.org/10.7556/jaoa.2016.079

37. Forehand M (2005) Blooms taxonomy: original and revised. In Orey M (ed) Emerging perspectives on learning, teaching, and technology. https://www.d41.org/cms/lib/ IL01904672/Centricity/Domain/422/BloomsTaxonomy.pdf

38. Davis AJ, Fierro L, Guptill M, Kiemeney M, Brown L, Smith DD, Young TP (2017) Practical application of educational theory for learning technical skills in emergency medicine. Ann Emerg Med 70(3):402-405. https://doi.org/10.1016/j.annemergmed.2017.04.026

39. Gale TCE, Chatterjee A, Mellor NE, Allan RJ (2016) Health worker focused distributed simulation for improving capability of health systems in Liberia. Simul Healthc 11(2):75-81. https://doi.org/10.1097/SIH.0000000000000156

40. Wier GS, Tree R, Nusr R (2017) Training effectiveness of a wide area virtual environment in medical simulation. Simul Healthc 12(1):28-40. https://doi.org/10.1097/ $\mathrm{SIH} / 0000000000000207$

41. Vince Lombardi Jr. https://www.goodreads.com/quotes/29093-practice-does-not-make-per fect-perfect-practice-makes-perfect

42. Ericsson KA (2008) Deliberate practice and acquisition of expert performance: a general overview. Acad Emerg Med 15:988-994

43. Ericsson KA (2008) Deliberate practice and the acquisition of expert performance: a general overview. Acad Med 15(11):988-994

44. Pusic MV, Boutis K, McGaghie WC (2018) Role of scientific theory in simulation education research. Simul Healthc 13(3S):S7-S14. https://doi.org/10.1097/SIH.0000000000000282

45. Munro A, Clark RE (2013) Cognitive task analysis-based design and authoring software for simulation training. Mil Med 178(October Suppl):7-14. https://doi.org/10.7205/MILMEDD-13-00265

46. Chiniara G, Cole G, Brisban K, Huffman D, Cragg B, Lamacchia M, Norman D, Canadian Network for Simulation in Healthcare Guidelines Working Group (2013) Simulation in healthcare: a taxonomy and a conceptual framework for instructional design and media selection. Med Teach 35:e1380-e1395. https://doi.org/10.3109/1042159X.2012.733451 
47. Sawyer T, Eppich W, Brett-Fleegler M, Grant V, Cheng A. More than one way to debrief: a critical review of healthcare simulation debriefing methods. Simul Healthc 11(3). https://doi. org/10.1097/SIH.0000000000000148

48. Moore GS, Perlow A, Judge C, Koh H (2006) Using blended learning in training the public health workforce in emergency preparedness. Public Health Rep 121:217-221

49. Dankbaar MEWP, Roozeboom MB, Oprins EAPBP, Rutten F, van Merrienboer JJG, van Saase JLCM, Shuit SCE (2017) Preparing residents effectively in emergency skills training with a serious game. Simul Healthc 12(1):9-16. https://doi.org/10.1097/SIH. 0000000000000194

50. Ingrassia PL, Ragazzoni L, Tengattnini M, Carenzo L, Della Corte F (2014) Nationwide program of education for undergraduates in the field of disaster medicine: development of a core curriculum centered on blended learning and simulation tools. Prehosp Disaster Med 29(5):508-515. https://doi.org/10.1017/S1049023X14000831

51. Chandler T, Qureshi K, Gebbie KM, Morse SS (2008) Teaching emergency preparedness to public health workers: use of blended learning in web-based training. Public Health Rep 123:676-680

52. Phrampus PE, O”Donnell JM, Farkas D, Abernathy D, Brownlee K, Dongilli T, Martin S (2016) Rapid development and deployment of Ebola readiness training across an academic health system. Simul Healthc 11(2):82-88. https://doi.org/10.1097/SIH.000000000000013

53. Miller JL, Rambeck JH, Snyder A (2014) Improving emergency preparedness system readiness through simulation and interprofessional education. Public Health Rep 129(Suppl 4):129-135

54. Brydges R, Nair P, Ma I, Shanks D, Hatala R (2012) Directed self-regulated learning versus instructor-regulated learning in simulation training. Med Educ 46:648-656. https://doi.org/ 10.1111/j.1365-2923.2012.04268.x

55. Issenberg SB, Scalese RJ (2008) Simulation in health care education. Perspect Biol Med 51(1):31-46. Johns Hopkins University Press. https://doi.org/10.1353/pbm.2008.0004

56. Woodruff AE, Jensen M, Loeffler W, Avery L (2014) Advanced screencasting with embedded assessments in pathophysiology and therapeutics course modules. Am J Pharm Educ 78(6):Article 128

57. Verheul MLMI, Duckers MLA, Visser BB, Beerens RJJ, Bierens JJJLM (2018) Disaster exercises to prepare hospitals for mass-casualty incidents: does it contribute to preparedness or is it ritualism? Prehosp Disaster Med 33(4):387-393

58. Triola MM, Campion N, McGee JB, Albright S, Greene P, Smothers V, Ellaway R (2007) An XML standard for virtual patients: exchanging case-based simulations in medical education. AMIA Ann Symp Proc AMIA Symp 2007:741-745

59. Padilla JJ, Diallo SY, Armstrong RK (2018) Toward live virtual constructive simulations in healthcare learning. Simul Healthc 13:S35-S40

60. Noble C (2002) The relationship between fidelity and learning in aviation training and assessment. J Air Transp 7(3):33-49

61. Rehman A, Mitman R, Reynolds M (1995) A handbook of flight simulation requirements for human factors research, Technical report no. DOT/FAA/CT-TN96/46. Crew Systems Ergonomics Information Analysis Center, Wright-Patterson AFB

62. Diekmann P, Gaba D, Rall M (2007) Deepening the theoretical foundations of patient simulation as social practice. Simul Healthc 2:183-193

63. Hamstra SJ, Brydges R, Hatala R, Zendejas B, Cook DB (2014) Reconsidering fidelity in simulation-based training. Acad Med 89(4):387-392. https://doi.org/10.1097/ACM. 0000000000000130

64. Talbot TB (2013) Balancing physiology, anatomy, and immersion: how much biological fidelity is necessary in a medical simulation? Mil Med 178:28-36. https://doi.org/10.7205/ MLMED-D-13-00212

65. Kyaw Tun J, Alinier G, Tang J (2015) Redefining simulation fidelity for healthcare education. Simul Gaming 46(2):159-174. https://doi.org/10.1177/1046878115576103 
66. Hart D, Rush R, Rule G, Clinton J, Beilman G, Anders S, Brown R, McNeil MA, Reihson T, Chipman J, Sweet R (2017) Training and assessing critical airway, breathing, and hemorrhage control procedures for trauma care: live tissue versus synthetic models. Acad Emerg Med. https://doi.org/10.1111/acem.13340

67. Savage EC, Tenn C, Vartanian O, Blackler K, Sullivan-Kwantes W, Garrett M, Blais A, Jarmasz J, Peng H, Pannell D, Tien HC (2015) A comparison of live tissue training and highfidelity patient simulator: a pilot study in battlefield trauma training. J Trauma Acute Care Surg 79(4, Suppl 1):S157-S163. https://doi.org/10.1097/TA0000000000000668

68. Hauglum SD et al (2018) Evaluation of a low-cost, high-fidelity animal model to train graduate advanced practice nursing students in the performance of ultrasound-guided central line catheter insertion. Simul Healthe 13(5):341-347

69. Advanced Modular Manikin. https://www.advancedmodularmanikin.com/about.html

70. Bewley WL, O’Neil HF (2013) Evaluation of medical simulations. Mil Med 178:64-75

71. Patel V, Aggarwal R, Cohen D, Taylor D, Darzi A (2013) Implementation of an interactive virtual-world simulation for structured surgeon assessment of clinical scenarios. J Am Coll Surg 217(2):270-279. https://doi.org/10.1016/j.jamcollsurg.2013.03.023

72. Bai X, Duncan RO, Horowitz BP, Graffeo JM, Godstein SL, Lavin J (2012) The added value of 3D simulations in healthcare education. Int J Nurs Educ 4(2):67-72

73. Cohen D, Sevdalis N, Patel V (2013) Tactical and operational response to major incidents: feasibility and reliability of skills assessment using novel virtual environments. Resuscitation 84:992-998

74. Wilkerson W, Avstreih D, Gruppen L, Beier KP, Woolliscroft J Using immersive simulation for training first responders for mass casualty incidents. Acad Emerg Med 15:1152-1159. https://doi.org/10.1111/j.1553-2712.2008.00223.x

75. Heinrichs WL, Youngblood P, Harter P, Kusumoto L, Dev P (2010) Training healthcare personnel for mass-casualty incidents in a virtual emergency department: VED II. Prehosp Disaster Med 25(5):424-432

76. Lino JA, Gomes GC, Sousa NDSVC, Carvalho AK, Dinez MEB, Junior ABV (2016) A critical review of mechanical ventilation virtual simulators: is it time to use them? JMIR Med Educ 2(1):e8. https://doi.org/10.2196/mededu.5350

77. Foronda CL, Alfes CM, Dev P, Kleinheksel AJ, Nelson DA, O’Donnell JM, Samosky JT (2017) Emerging technologies in nursing education. Nurse Educ 42(1):14-17. https://doi. org/10.1097/NNE.000000000000295

78. Koenig K (2010) Editorial comments-training healthcare personnel for mass casualty incidents in a virtual emergency department: VED II. Prehosp Disaster Med 25(5):433-434

79. Ingrassia PL et al (2015) Virtual reality and live simulation: a comparison between two simulation tools for assessing mass casualty triage skills. Eur J Emerg Med 22:121-127

80. Farra S, Miller ET (2012) Integrative review: virtual disaster training. J Nurs Educ Pract 3(3):93-101. https://doi.org/10.5430/jnep.v3n3p93

81. Andreatta PB, Maslowski SE, Petty S, Shim W, Marsh M, Hall T, Stern S, Frankel J (2010) Virtual reality triage training provides a viable solution for disaster-preparedness. Acad Emerg Med 17(8):870-876. https://doi.org/10.1111/j.1553-2712.2010.00728.x

82. Kizakevich PN, Lux 1, Steve Duncan S, Curry Guinn C (2003) Virtual simulated patients for bioterrorism preparedness training. Stud Healthc Inform 94:165-167

83. Foronda CL, Shubeck K, Swoboda SM, Hudson KW, Budhathoki C, Sullivan N, Hu X (2016) Impact of virtual simulationto tech concepts of disaster triage. Clin Simul Nurs 12(4):137-144. https://doi.org/10.1016/j.ecns.2016.02.004

84. Vincent DS, Sherstyuk A, Burgess LPA, Connolly K (2008) Teaching mass casualty triage skills using immersive three-dimensional virtual reality. Acad Emerg Med 15(11):1160-1165. https://doi.org/10.1111/j.1553-2712.2008.00191.x

85. Youngblood P, Harter PM, Srivastava S, Moffett S, Heinrichs WL, Dev P (2008) Design, development, and evaluation of an online virtual emergency department for training trauma teams. Simul Healthc 3(3):146-153 
86. Ragazzoni L, Ingrassia L, Echeverri L, Maccapani F, Berryman L, Burkle F, Della Corte F (2015) Virtual reality simulation training for Ebola deployment. Disaster Med Public Health Prep 9(5):543-546. https://doi.org/10.1017/dmp.2015.36

87. Pucher PH, Batrick N, Taylor D, Chaudery M, Cohen D, Darzi A (2014) Virtual-world hospital simulation for real-world disaster response: design and validation of a virtual reality simulator for mass casualty incident management. J Trauma Acute Care Surg 77(2):315-321

88. Hsu EB, Jenckes MW, Catlett CL, Robinson KA, Feuerstein C, Cosgrove SE, Green GB, Bass EB (2004) Effectiveness of hospital staff mass casualty incident training methods: a systematic literature review. Prehosp Disaster Med 19(3):191-199

89. Lineberry M, Dev P, Lane HC, Talbot TB (2018) Learner-adaptive educational technology for simulation in healthcare: foundations and opportunities. Simul Healthc 13(3S):S21-S27. https://doi.org/10.1097/SIH.0000000000000274

90. Federal Emergency Management Agency (2018) Homeland Security Exercise Evaluation Program. Retrieved from: https://www.fema.gov/hseep

91. Hanson K, Hernandez L, Banaski JA (2018) Building simulation exercise capacity in Latin America to manage public health emergencies. Health Secur 16:S98-S102

92. World Health Organization (2017) WHO Simulation Exercise Manual. World Health Organization, Geneva

93. WHO concept note: development, monitoring and evaluation of functional core capacity for implementing the International Health Regulations (2005) http://www.who.int/ihr/publica tions/concept_note_201407.pdf?ua=1

94. Weiner SG, Totten VY, Jacquet GA, Douglass K, Birnbaumer DM, Promes SB, Martin IBK (2013) Effective teaching and feedback skills for international emergency medicine "train the trainers" programs. J Emerg Med 45(5):718-725. https://doi.org/10.1016/j.jemermed. 2013.04.040

95. Gillett B, Peckler B, Sinert R, Onkst C, Nabors S, Issley S, Maguire C, Galwankarm S, Arquilla B (2008) Simulation in a disaster drill: comparison of high-fidelity simulators versus trained actors. Acad Emerg Med 15:1144-1151. https://doi.org/10.1111/j.15532712.2008.00198.x

96. Claudius I, Kaji A, Santillanes G, Cicero M (2015) Comparison of computerized patients versus live moulaged actors for a mass-casualty drill. Prehosp Disaster Med 30(5):438-432. https://doi.org/10.1017/S1049023X15004963

97. Ingrassia PL, Prato F, Geddo A, Colombo D, Tengattini M, Calligaro S, La Mura F, Franc JM, Della Corte F (2010) Evaluation of medical management during a mass casualty incident exercise: an objective assessment tool to enhance direct observation. J Emerg Med 39:629-636

98. Rojo E, Oruna C, Sierra D, Garcia G, Del Moral I, Maestre JM (2016) Simulation as a tool to facilitate practice changes in teams taking care of patients under the investigation for Ebola virus disease in Spain. Simul Healthc 11(2):89-93. https://doi.org/10.1097/SIH. 0000000000000139

99. Menkin-Smth L, Lehman-Huskamp K, Schaefer J, Alfred M, Catchpole K, Pockrus B, Wilson DA, Reves JG (2018) A pilot trial of online simulation training for Ebola response training. Health Secur 16(6). https://doi.org/10.1089/hs.2018.0055

100. Delaney HM, Lucero PF, Maves RC, Lawler JV, Maddry JK, Biever KA, Murray CK (2016) Ebola virus disease simulation case series patient with ebola virus disease in the prodromal phase of illness (scenario 1), the "wet" gastrointestinal phase of illness (scenario 2), and the late, critically ill phase of disease (scenario 3). Simul Healthc 11(2):106-116. https://doi.org/ 10.1097/SIH.0000000000000115

101. Biddell EA, Vandersall BL, Bailes SA, Estephan SA, Ferrara LA, Nagy KM, O'Connell JL, Patterson MD (2016) Use of simulation to gauge preparedness for Ebola at a free-standing children's hospital. Simul Healthc 11(2):94-99. https://doi.org/10.1097/SIH. 0000000000000134

102. Drew JL, Turner J, Mugele J, Hasty G, Duncan T, Zaiser R, Cooper D (2016) Beating the spread: developing a simulation analog for contagious body fluids. Simul Healthc 11:100-105. https://doi.org/10.1097/SIH.0000000000000157 
103. Davis MA, Landesman R, Tadmor B (2008) Initial test of emergency procedure performance in temporary negative pressure isolation by using simulation technologies. Ann Emerg Med 51(4):420-425

104. Marlow SL, Bedwell WL, Zajac S, Reyes DL, LaMar M, Khan S, Lopreiato J, Salas E (2018) Multiple patient casualty scenarios: a measurement tool for teamwork. Simul Healthc 13(6):394-403

105. Wang R, DeMaria S, Goldberg A, Katz D (2016) A systematic review of serious games in training health care professionals. Simul Healthc 11(1):41-51. https://doi.org/10.1097/ SIH000000000000118

106. Taekman JM, Shelley K (2010) Virtual environments in healthcare: immersion, disruption, and flow. Int Anesthesiol Clin 48(3):101-121

107. Thompson D, Baranowski T, Buday R, Baranowski J, Thompson V, Jago R, Griffith J (2010) Simul Gaming. August 1; 41(4): 587-606. https://doi.org/10.1177/ 1046878108328087

108. Graafland M, Dankbaar M, Mert A, Lagro J, De Wit-Zuurendonk L, Schuit S, Schaafstal A, Schijven M (2012) How to systematically assess serious games applied to health care. JMIR Serious Games 2(2):e11. https://doi.org/10.2196/games.3825

108A. Graafland M, Bemelman WA, Schijven MP (2017) Game-based training improves the surgeon's situational awareness in the operation room: a randomized controlled trial. Surg Endosc. https://doi.org/10.1007/s00464-017-5456-6

109. Pasquier P, Merat S, Malgras B, Petit L, Queran X, Bay C, Boutonnet M, Jault P, Ausset S, Auroy Y, Perez JP, Tesniere A, Pons F, Mignon A (2016) A serious game for massive training and assessment of French soldiers involved in forward combat casualty care (3D-SC1): development and deployment. JMIR Serious Games 4(1):e5. https://doi.org/10. 2196/games.5340

110. Planchon J, Vacher A, Comblet J, Rabatel E, Darses F, Mignon A, Pasquier P (2017) Serious game training improves performance in combat life-saving interventions. Injury 49:86-92. https://doi.org/10.1016/j.injury.2017.10.025

111. Mohan D, Farris C, Fischhoff B, Rosengart MR, Angus DC, Yealy DM, Wallace DL, Barnato AE (2017) Efficacy of educational video game versus traditional educational apps at improving physician decision making in trauma triage: randomized controlled trial. $\mathrm{Br}$ Med J 359:5416. https://doi.org/10.1136/bmj.j5416

112. Mayer RE (2016) What should be the role of computer games in education? Policy Insights Behav Brain Sci. https://doi.org/10.1177/2372732215621311

113. Koenig A, Iseli M, Wainess R, Lee JJ (2013) Assessment methodology for computer-based instructional simulations. Mil Med 178(October Suppl):47-54. https://doi.org/10.7205/ MILMED-D-13-00217

114. Giunti G, Baum A, Giunta D, Plazzotta F, Benitez S, Gomez A, Luna D, Gonzolez F, de Quiros B (2015) Serious games: a concise overview on what they are and their potential applications to healthcare. Medinfo 2015. https://doi.org/10.3233/978-1-61499-564-7-386

115. Olszewski AE, Wolbrink TA (2017) Serious gaming in medical education: a proposed structured framework for game development. Simul Healthc 12(4):240-253

116. Kneebone R, Arora S, King D (2010) Distributed simulation-accessible immersive training. Med Teach 32(1):65-70

117. Ohta K, Kurosawa H, Shiima Y, Ikeyama T, Scott J, Hayes S, Gould M, Buchanan N, Nadkarni V, Nishisaki A (2017) The effectiveness of remote facilitation in simulation-based pediatric resuscitation training for medical students. Pediatr Emerg Care 33(8):564-556

118. Von Lubitz DKJE, Levine H, Patricelli F, Richir S (2008) Distributed simulation-based clinical training: going beyond the obvious. In: Kyle RR, Murray WB (eds) Clinical simulation operations, engineering, and management. Academic, Burlington, pp 591-622

119. Ali J, Sorvari A, Camera S, Kinach M, Mohammed S, Pandya A (2013) Telemedicine as a potential medium for teaching the Advanced Trauma Life Support (ATLS) course. J Surg Educ 70(2):258-264. https://doi.org/10.1016/j.jsurg.2012.11.008

120. Andreatta $P$ (2017) Healthcare simulation in resource-limited regions and global health applications. Simul Healthc 12(3):135-138. https://doi.org/10.1097/SIH.0000000000000220 
121. Stegmann K, Pilz F, Siebeck M, Fischer F (2012) Vicarious learning during simulations: is it more effective than hands-on training? Med Educ 46:1001-1008. https://doi.org/10.1111/j. 1365-2923.2012.04344.x

122. Perry MF, Seto TL, Vasquez JC, Josyula S, Rule ARL, Rule DW, Kamath-Rayne BD (2018) The influence of culture on teamwork and communication in a simulation-based resuscitation training at a community hospital in Honduras. Simul Healthc 13(5):363-370. https://doi. org/10.1097/SIH.000000000000323

123. Pitt MB, Eppich WJ, Shane ML, Butteris SM (2017) Using simulation in global health. Simul Healthc 12(3):177-181. https://doi.org/10.1097/SIH.0000000000000209

124. Ikeyama T, Shimizu N, Ohta KD (2012) Low-cost and ready-to-go remote-facilitated simulation-based learning. Simul Healthc 7(1):35-39

125. Erickson D, Greer L, Belard A, Tinnel B, O’Connell J (2010) A hybrid integrated services digital network-internet protocol solution for resident education. Telemed E-Health. https:// doi.org/10.1089/tmj.2009.0132

126. Kim H (2017) Experience of simulation-based training in a developing country. Simul Healthc 12(3):202. https://doi.org/10.1097/SIH.0000000000000203

127. Smith-Stoner M (2009) Web-based broadcast of simulations. Nurse Educ 34(6):266-269

128. Hayden EM, Navedo DD, Gordon JA (2012) Web-conferenced simulation sessions: a satisfaction survey of clinical simulation encounters via remote supervision. Telemed E-Health 18(7):525-529

129. Christensen MD, Oestergaard D, Dieckmann P, Watterson LM (2018) Learners' perceptions during simulation-based training: an interview study comparing remote versus locally facilitated simulation-based training. Simul Healthc 13(5):306-315. https://doi.org/10. 1097/SIH.0000000000000300

130. Cameron M, Ray R, Sabesan S (2015) Remote supervision of medical training via videoconferencing in northern Australia: a qualitative study of the perspectives of supervisors and trainees. Br Med J Open 5:e06444

131. Christensen MD, Rieger K, Tan S, Dieckmann P, Oestergaard D, Watterson LM (2015) Remotely versus locally facilitated simulation-based training in management of the deteriorating patient by newly graduated health professionals. Simul Healthc 10(6):352-359. https://doi.org/10.1097/SIH.0000000000000123

132. Ahmed R, Gardner AK, Atkinson SS, Gable B (2014) Teledebriefing: connecting learners to faculty members. Clin Teach 11:270-273

133. Gerhardt R, Berry J, Mabry R, Fluornoy L, Arnold RG, Hults C, Robinson JB, Thaxton RA, Cestero R, Heiner JD, Koller AR, Cox K, Patterson JN, Dalton WR, McKeague AL, Gilbert G, Manemeit C, Adams BD (2014) Evaluation of contingency telemedical support to improve casualty care at a simulated military intermediate resuscitation facility: the EM-ANGEL study. J Spec Med Oper Med 14(1):50-57

134. Modeling and Simulation Committee (2011) A primer on modeling and simulation. National Training and Simulation Association

135. Arbon P, Bottema M, Zeitz K, Lund A, Turris S, Anikeeva O, Steenkamp M (2018) Nonlinear modelling for predicting patient presentation rates for mass gatherings. Prehosp Disaster Med 33(4):362-367. https://doi.org/10.1017/S1049023X18000493

136. Zhang X, Meltzer MI, Wortley PM (2006) FluSurge- a tool to estimate demand for hospital services during the next pandemic. Med Decis Mak 26(6):617-623. https://doi.org/10.1177/ 0272989X06295359

137. Hospital Surge Evaluation Tool. Public Health Emergency website. https://www.phe.gov/ preparedness/planning/hpp/surge/pages/default.aspx

138. Carr BG, Walsh L, Williams JC, Pryor JP, Branas CC (2016) A geographic simulation model for the treatment of trauma patients in disasters. Prehosp Disaster Med 31(4):413-421. https://doi.org/10.1017/S1049023X1600510

139. Mumma BE, McCue JY, Li CS, Holmes JF (2014) Effects of emergency department expansion on emergency department patient flow. Acad Emerg Med 21(5):504-509. https://doi.org/10.1111/acem.12366 
140. Kaji AH, Bair A, Okuda Y, Kobayashi L, Khare R, Vozenilek J (2008) Defining systems expertise: effective simulation at the organizational level- implications for patient safety, disaster surge capacity, and facilitating the systems interface. Acad Emerg Med 15(11):1098-1103

141. Toerper MF, Kelen GD, Sauer LM, Bayrum JD, Catlett C, Levin S (2017) Hospital surge capacity: a web-based simulation tool for emergency planners. Disaster Med Public Health Prep 12(4):513-522. https://doi.org/10.1017/dmp2017.93

142. Khare RK, Powell ES, Reinhardt G, Lucenti M (2009) Adding more beds to the emergency department or reducing admitted patient boarding times: which has a more significant influence on emergency department congestion? Ann Emerg Med 53(5):575-585. https:// doi.org/10.1016/j.annemergmed.2008.07.009

143. Franc JM, Ingrassia PL, Verde M, Colombo D, Della Corte F (2015) A simple graphical method for quantification of disaster management surge capacity using computer simulation and process-control tools. Prehosp Disaster Med 33(4):387-393

144. Ohta S, Yoda I, Takeda M, Kuroshima S, Uchida K, Kawai K, Yukioka T (2015) Evidencebased effective triage operation during disaster: application of human-trajectory data to triage drill sessions. Prehosp Disaster Med 30(1):102-109. https://doi.org/10.1017/ S1049023X14001381

145. Pennathur PR, Cao D, Sui Z, Lin L, Bisantz AM, Fairbanks RJ, Guarrera TK, Brown JL, Perry SJ, Wears R (2010) Development of a simulation environment to study emergency department information technology. Simul Healthc 5(2):103-111. https://doi.org/10.1097/ SIH.0b013e3181c82c0a

146. Klein MG, Reinhardt G (2012) Emergency department patient flow simulations using spreadsheets. Simul Healthc 7(1):40-47

147. Hill M (2011) Disaster medicine: using modeling and simulation to determine medical requirements for responding to natural and man-made disasters. Report no. 10-38, Naval Health Research Center. https://apps.dtic.mil/dtic/tr/fulltext/u2/a561719.pdf

148. Embrey EP, Clerman R, Gentilman MF, Cecere F, Klenke W (2010) Community-based medical disaster planning: a role for the department of defense and the military health system. Mil Med 175:298-300 